\title{
Information Rx: Prescribing Good Consumerism and Responsible Citizenship
}

\author{
Samantha Adams · Antoinette de Bont
}

Published online: 17 August 2007

(C) Springer Science+Business Media, LLC 2007

\begin{abstract}
Recent medical informatics and sociological literature has painted the image of a new type of patient - one that is reflexive and informed, with highly specified information needs and perceptions, as well as highly developed skills and tactics for acquiring information. Patients have been re-named "reflexive consumers." At the same time, literature about the questionable reliability of web-based information has suggested the need to create both user tools that have pre-selected information and special guidelines for individuals to use to check the individual characteristics of the information they encounter. In this article, we examine suggestions that individuals must be assisted in developing skills for "reflexive consumerism" and what these particular skills should be. Using two types of data (discursive data from websites and promotional items, and supplementary data from interviews and ethnographic observations carried out with those working to sustain these initiatives), we examine how users are directly addressed and discussed. We argue that these initiatives prescribe skills and practices that extend beyond finding and assessing information on the internet and demonstrate that they include ideals of consumerism and citizenship.
\end{abstract}

Keywords Internet · Reflexive consumerism · Reliability initiatives

\section{Introduction}

In discussions about the increasing use of internet technologies in health care a new kind of patient has slowly been constructed-a patient that is reflexive and

\section{S. Adams $(\bowtie) \cdot$ A. de Bont}

Department of Health Policy and Management, Erasmus University Medical Center, Postbus 1738, Woudestein, L Building, 3000DR Rotterdam, The Netherlands

e-mail: s.adams@erasmusmc.nl

A. de Bont

e-mail: a.debont@erasmusmc.nl 
informed, with highly specified information needs and perceptions, as well as highly developed skills and tactics for acquiring information. This specific depiction of the patient transforms the patient into an active participant in his or her care, "empowered" through training, skill development and the use of technologies such as the world wide web, all of which can be provided or enabled by government organizations or other political actors. Through increased access to medical information coming from outside of the health care arena the boundary between lay and expert is breaking down, enabling patients to become experts, be more assertive in managing their own care and change the nature of their existing relationships with health care professionals [6, 27, 28].

As Henwood et al. [31] point out, however, just because the potential for empowerment exists, it does not necessarily occur. Patients conform only with difficulty to the images associated with the reflexive consumer, and the concept of the "informed patient" is empirically difficult to sustain [41]. Becoming informed requires skills related both to information and to the various media that can be used to access that information. Patients reflect low-level skills with respect to searching for information, rely on intermediaries, and experience concrete barriers during the medical encounter, all of which act as actual constraints on the emergence of informed patients [31, 32].

In literature about the questionable reliability of web-based information, the suggestion that lay information seekers are constrained in conforming to this image is too mild. This body of literature asserts the stronger position that they are actually prevented from being empowered because of the large amount of information and the questionable quality of much of that information. Central in this discussion is the concern that even if patients manage to find web-based medical information, they lack the skills necessary to evaluate the quality of that information, and therefore are especially vulnerable to harmful information in the form of errors, fraud and "quackery" [16, 17, 34, 35, 50, 51]. This concern is answered by the argument that a pressing need exists for educating patients in how to judge a website's reliability $[10,18,19,23,33,48,50,54]$.

Taken together, these discourses construct patients-as-web-users that are simultaneously skilled and capable, but also incompetent and unskilled. The informed patient must be educated in how to search for and assess information in order to conform to the definition of a reflexive, empowered consumer. Patients are not empowered merely through access to the internet or web-based information $[1,49]$, but, this literature suggests, must be constructed in the process of being led to pre-selected information by health professionals and information specialists. In suggesting the need to create user tools that have pre-selected information, as well as guidelines for patients to use to check the individual characteristics (author, sources, date, underlying financial sponsorship, etc.) of the information they encounter, authors emphasize the boundary between lay and expert assessments of information, privileging the latter over the former. Existing literature prescribes that patients utilize government-provided medical/health portals, click on hyperlinked icons (seals of approval or "trust marks") provided by non-profit or nongovernmental organizations, follow checklists created by professionals or health 
educators, and/or download special toolbars, all of which will assist them in finding and evaluating information on the web.

Because web pages provide powerful examples of pre-defining (or pre-confining) how information technologies should work, how they should be perceived and how different actors should utilize them, it is important to study the discourses that they carry [43]. However, little attention has been given to the underlying prescriptions about skills and use, as well as additional political agendas and messages about individual behavior, that individual web-based reliability initiatives, such as portals, seals and special toolbars, convey. In this article, we look not at how patients assess information (or what skills they do/not reflect), but rather, at what health educators, medical professionals and review organizations suggest the skills of a reflexive consumer should be. ${ }^{1}$ We view the various user tools, such as guidelines, checklists portals, and clickable seals, as artifacts with politics [56] - particularly, the politics of building consumer-citizens and shaping their skills, perceptions and behaviors. We begin by looking at more general literature about the construction of users and designers, followed by a review of literature that transforms potentially informed patients into reflexive consumers. Using two types of data: "front page" data (information, images, quotes gleaned directly from websites and their accompanying promotional items) and supplementary "behind the scenes" data from interviews and observations carried out with those working to sustain given initiatives, we examine how users are directly addressed and discussed. How are users enrolled by sites and promotional items? What ideals are represented in these user tools and in what kind of practices are they embedded? We argue that, although these examples claim to target "all citizens," the prescriptions for action that these user tools carry suggest that the user envisioned by the developers of these tools is not everybody, but rather a specific, ideal type of user: the good consumer/ responsible citizen. ${ }^{2}$ In order to develop skills for finding and assessing information on the internet, patients must engage in certain practices - practices that also enable developing the skills necessary to share the responsibility for information reliability and to be an empowered health consumer and responsible citizen.

\section{The Importance of the State in Configuring Users of Technologies}

Studies of science, technology and society (STS) have a long tradition of reflecting on how users are or are not included in the design and implementation of different technologies. ${ }^{3}$ Woolgar [58] argues that designer preconceptions about use can shape what counts as legitimate behavior and that users are "configured," i.e.: their identity and skills are defined and constraints upon their (possible, future) actions are set, before the technologies ever reach the anticipated user group. Because of

\footnotetext{
1 Adams et al. [4] discuss how Dutch patients assess the reliability of information and how their assessment strategies relate to the tools designed to help them.

2 See the work of Latour $[39,40]$ for a discussion of translation with respect to the use of technology. See Oudshoorn et al. [47] for further discussion on how configuring users as "everybody" can constrain design.

${ }^{3}$ For a thorough review of this body of literature, see Oudshoorn and Pinch [46].
} 
this configuring, technologies can be read as carrying specific scripts for use [5]. Rose and Blume [52], however, have criticized much of the subsequent work on configuring users because it attributes configuration largely to market-driven design and pays too little attention to the possibility of states as providers or enablers of technology use, and therefore neglects to consider the potential role states have in user configuration.

According to Rose and Blume, focusing on technologies that are developed or facilitated by the state and its institutions may highlight significant tensions between individuals as users and the state of which they are members and citizens. Policy documents can develop meanings for information technologies by providing, for example, the language of discourse about those technologies [38]. In their behavior and discourse, collective providers, much like market-like providers, presume that individuals will be active consumers of technologies, meaning that the state may enact policies that, while not overtly or explicitly configuring the user, do create or maintain an environment that helps to shape how users are configured. In using certain technologies (or by using them in the specified ways), individuals fit with their configurations and follow the technologies' scripts and actualize their potential as "good" citizens [52].

Singleton [53] makes a similar point with her suggestion that the New Public Health in the UK seeks to train citizens in more ways than one. She asserts that training programs for healthy citizens are not just about physical health but also about practical skills and about distinguishing between active and inactive citizens. Klecun-Dabrowska and Cornford [38] have also looked at the recent discourses on health in the UK, specifically focusing on the role of telemedicine within wider national and international debates on health. They, too, saw that documents convey a vision of a refocused health care system to serve a population that has enough information resources to enable individuals to manage their own care and participating more actively in the health care process. Information, they argue, is transformed into something that is easily captured, understood and transformed to achieve wider goals-goals related to social responsibility and community values.

At the same time, states want to forward their political agendas and invent new modes of indirect steering for empowering their members such that they freely, willingly and self-reflexively choose the paths toward the desired outcomes of the state. The possibility of the state to directly influence its citizens is made relative, as the state competes with other types of influences. This has led to the development of new types of steering, where governments seek to rule the social indirectly through designing, facilitating and moderating processes of self- and co-governance [8]. More communicative and cooperative modes of re-centering allow for bottom up articulation, without relinquishing everything to citizen preferences. Again, these programs are not just about the empowerment of individuals or about the distribution of expertise, but are also about distinguishing between active and inactive citizens. Although states demonstrate a readiness to engage in active teamwork and argue the need for collaborative solutions, Bang argues that they nonetheless reveal how key relationships are re-imagined and redrawn.

Two things are worthy of note: first, the terms "re-imagining" and "redrawing" suggest that something new can emerge, which is a distinct possibility. However, 
with respect to the internet, at least, studies have shown that the boundaries that are constructed around information, for example, tend to reinforce existing social ideas [49] and geographic borders [26]. The lines that are redrawn serve only to reinforce what is already there. Second, the exclusive focus on states tends to neglect the role of other political actors. Especially in activities regarding reliable medical information, states are not alone, but are joined by non-governmental organizations (NGOs) and inter-governmental organizations (IGOs), as well as non-profit organizations voicing their own political advocacy agendas.

We extend the analysis in this paper to look at both programs from federal agencies and initiatives created by other types of political institutions. These programs and initiatives provide tools for accessing and assessing information on the web, in some cases enabling information provision. (See Textbox 1 for an overview of the different initiatives that are used as examples). ${ }^{4}$ For example, the US Department of Health and Human Services provides a portal with contact information for organizations (http:// www.healthfinder.gov) and the US National Library of Medicine (NLM) provides a portal with health content from the National Institutes of Health (http://www.medlineplus.gov). Outside of the US, the Health on the Net Foundation (HON) in Geneva seeks to raise awareness about ethical issues related to providing medical information, while the World Health Organization (WHO) proposes the creation of a ".health" domain afforded only to sites meeting specific criteria. ${ }^{5,6}$

These self-ascribed roles lead to numerous questions, such as why UN NGO status (in the case of HON) or a "neutral position" (claimed by the WHO) is crucial to building claims about the reliability of medical information. Why is a 'gov' domain "more reliable" than a '.com' and where does the '.org' domain rank in relation to other existing and proposed domains? What potential tensions arise between states and citizens (or even NGOs and citizens) in these settings? Although these questions would be difficult to answer, they do give us cause to think about the political messages that are sent to lay information seekers when they are instructed on how to search for, evaluate and use web-based medical information.

\footnotetext{
${ }^{4}$ Because each of these examples is discussed individually elsewhere, we will not go into too much depth here. For a historical review of all of the initiatives, see Adams and Berg [2]. See also Adams and De Bont [3] for a review of the different notions of reliability that emerge from healthfinder, HON and Quackwatch, and Adams and Bal [1] for a discussion about how review work reinforces existing boundaries in the case of NLM and HON.

5 The health domain was rejected by ICANN (the organization responsible for assigning domain names), and an alternative failed to emerge from discussions [11]; however, the WHO has entered into action in this area by producing a list of recommended websites for information on vaccinations on its home page [57]

${ }^{6}$ Each of these institutions, with the exception of Medlineplus (and the health domain had it come to fruition), leads patients to primary health content information on other sites. Medlineplus provides primary health content information that is derived from the US National Institutes of Health (of which the National Library of Medicine is a part). However, even Medlineplus has a different level of interaction with its users than, for example, NHS Direct in the UK, which was not included in this study. Whereas the National Library has contact with focus groups in order to improve the Medlineplus website, NHS Direct offers the potential for personal contact at the moment an individual is searching for health services or information. For this reason, such an initiative would also be an interesting point to study an reflect upon in the context of this analysis.
} 
Textbox 1 Overview of home pages for cited examples

Healthfinder is the official Federal Gateway to health information, provided by the US Department of Health and Human Services http://www.healthfinder.gov

Medlineplus is a portal provided by the US National Library of Medicine http://www.medlineplus.gov

Quackwatch seeks to combat health fraud and is run by Dr. Stephen Barrett http://www.quackwatch.org

Health on the Net is a Geneva-based non-governmental organization that provides diverse user tools. The focus of this study is the 8 principle HON Code of Conduct and accompanying hyperlinked seal http:// www.hon.ch

MedCERTAIN was funded by the EU from 2000-2002under the "Action Plan on promoting safer use of the Internet by combating illegal and harmful content on global networks". The collaborative

MedCIRCLE is a follow-up that provides users with a downloadable toolbar http://

www.medcertain.org; http://www.medcircle.org

TNO's QMIC is a three-tiered trust mark for medical websites in the Netherlands. The third tier signifies content review of information http://www.qmic.nl/qmic/home.do

The World Health Organization recently released a list of approved sites for vaccine safety http:// www.who.int/immunization_safety/safety_quality/approved_vaccine_safety_websites/en/

\section{Informed Patients...Reflexive Consumers...Ideal Citizens?}

This entire line of discourse about empowering patients and the role of web-based information has led to the semantic challenge of properly naming those nonmedically trained individuals searching for information online. For example, the term patient does not encapsulate those persons who search for information regarding the health situation of a family member or friend. Miller and Reents' [44] alternative, "information retrievers", makes the user too passive, while the suggested informatics alternative "medical end-users," [22] makes the route to the information too technology specific, without reflecting the social aspects of information use and broader information "landscapes" [13, 29, 32] that persons can access. Furthermore, the term medical does not reflect broader issues related to health and fails to allow for use of information by those that Kivits [36] calls "healthy internet users," those not necessarily afflicted by illness, but nonetheless interested in health information.

The concepts "citizen" and "consumer" are terms for users that are used most often by those creating different web-based reliability initiatives, working under the suggestion that these terms are neutral and avoid the semantic problems mentioned above [see, for example, 7, 9, 45]. However, these words also carry connotations; Anderson et al. even go so far as to state, "When speaking about consumers, from this model it should become clear that we mainly refer to educated patients with chronic diseases from developed countries" (2003: 72). Using these two terms more generally implies certain rights, such as Gustafson and Wyatt's [25] assertion that consumers deserve both high quality content and a certain degree of confidence in the information they use, but such use also connotes certain responsibilities. Each of the initiatives to which the usage of these terms is attached defines particular types of participation that extend beyond gathering information to include activities in the health care process and social community at large. The consequence, of course, is that teaching patients how to search for and assess information on the web becomes 
more than just a process of constructing empowered patients-it extends further to inscribe notions of good consumerism and responsible citizenship.

When we couple the discussion about empowerment on the practical skills that users are expected to develop, we see that it takes place within an overt and dominant biomedical discourse [24], which is framed not only by medical professionals, but also by political actors. For example, in relation to assessing webbased health information, Edgar et al. [15] describe three essential skills: the ability to conduct a search and find the "right" sites; the ability to judge the quality of information found on a given site and the ability to synthesize that information into a useful context for personal/individual health. Eng and Gustafson [16] argue, however, that the skill is more than just assessing and using information, but is actually about deciding which of the existing tools works best for the individual. Only in finding the right tool can s/he implement a personal evaluative framework and learn how to be an educated consumer.

\section{How the Initiatives Enroll Citizens and Consumers}

Each of the initiatives discussed in this paper attempts to enroll internet users in specific activities of finding and assessing health information. The most prominent strategy of enrollment that we see is the suggestion of abounding risks to personal health and the simple ways to combat them. Involvement-learning how to check information actively and always - becomes a matter of personal responsibility and an identifying component of reflexive information consumption. Failure to learn about user tools and use them as prescribed is to be inactive, and therefore, deviant or lacking [52, 53].

\section{Highlighting Risks and Providing Simple Instructions for Combating Them}

One evident strategy for interesting patients in the need to check the reliability of the information is the construction of web-based information as information that puts individuals at risk. Because of the nature of the web, information can come from anyone, anywhere-it originates outside of a given country, in another medical tradition or health care context and as such it is foreign and worthy of suspicion. If information isn't pre-approved, individuals could be making their decisions based on wrong information, fraud, or quackery. An individual's health is potentially endangered because this information is always potentially just one mouse-click away and is difficult to distinguish from "truly reliable" information. In the language of this discourse, boundaries are constructed around information-these boundaries distinguish, for example, between geographic locations, but also reinforce more traditional ideas by distinguishing between lay persons and experts.

The proposed need to implement user education programs for checking the reliability of the information they encounter suggests that anyone online should be aware of this potential for harm and, therefore, actively involved in policing that information [21, 35]. HON, for example, currently includes information on its 
website about being a "vigilant user". Instructions about clicking and verifying proper use of its HONcode icon is prefaced by the following:

Unfortunately, we cannot banish incompetence or fraud from the medical Internet. If you come across a healthcare Web site that you believe is either possibly or blatantly fraudulent and does NOT display the HONcode, please alert Quackwatch. Of course, if such a site DOES display the HONcode, alert us immediately. HON cannot prevent dishonest operators from simply cutting and pasting the HONcode seal onto their Web sites in a bid to enhance their credibility. We do conduct our own random checks on subscribers to ensure they remain compliant with the HONcode. But we also rely heavily on vigilant Web surfers to alert us to dubious sites - and they do....There are three quick ways users can check whether a chosen site featuring our seal is a bona fide HONcode subscriber. ${ }^{7}$

HON points out to users that it needs its users to help police information on the internet. It invites them to join in a partnership with two types of authorities, the first being itself, an overarching political organization and the second being participants from the community of medical professionals. Active policing on the part of the user is made extremely simple and practically effortless - checking information is also as easy as a single mouse click (merely clicking on a small icon) or just running through a short checklist. ${ }^{8}$ Taking a few seconds can prevent all users from encountering bad information, whereas not checking could subject the user to fraudulent or otherwise harmful information. With its clickable trust mark ${ }^{9} \mathrm{HON}$ provides users with an easy tool to double check the background of the web information provider. This type of tool makes the action of checking information is made simple and non-time consuming - as easy as a mouse click. The MedCERTAIN project, which proposed a mechanism similar to HON's clickable seal, except that it proposed to include content review in addition to review of ethical principles, produced a prototype with the instruction, 'Remember to verify by simply clicking on it. ${ }^{10}$ Similarly, the Dutch QMIC trust mark states, 'In the blink of an eye, you can see that information is reliable and correct. ${ }^{11}$

The user that all of these organizations presuppose is someone who, like the project reviewers, is (or should be) familiar with the ethical issues underlying the provision of any, but especially medical, information on the web. We begin to see how political actors invent new modes of indirect steering for empowering users such that they choose specific paths. They attribute to these users skills and practices more in keeping with professional levels of information assessment and action. But

\footnotetext{
7 http://www.hon.ch/HONcode/audience.html

${ }^{8}$ We do not discuss checklists in depth here. For examples of such a checklists, see, http:// www.discern.org.uk or http://www.quick.org.uk. See also Eysenbach [20] and Bomba and Land [10].

9 See http://www.hon.ch/honcode.html for info on HON's ethical Code of Conduct and the HONCode icon placed on sites.

${ }^{10} \mathrm{http}: / / \mathrm{www} . \mathrm{medcertain}$. org/english/consumer/explanation.htm

11 Translated by the first author: "Zodat $\mathrm{u}$ in een oogopslag ziet dat de informatie betrouwbaar en inhoudelijk juist is." http://www.tno.nl/kwaliteit_van_leven/preventie_en_zorg/kwaliteit_in_de_zorg/ kwaliteitsborging_voor_in/
} 
they also make these practices "user friendly" by emphasizing the ease with which information can be checked, with little additional thought or demands on time, and by encouraging participation in partnerships with them.

\section{Directing Paths Toward Information}

The various initiatives also emphasize their links to the medical community and partnerships with one another. This is evident in at least three forms: logos from other departments and organizations placed on websites, joint projects with physician's organizations and overt statements about the best course of action that are located on websites. At the time of writing, HON's website includes the logos of the University Hospital, the EU, the city of Geneva and Sun Microsystems. The tag lines for each individual logo identify how these different groups provide social and technical support for $\mathrm{HON}$ and its web activities. These logos show that HON is part of a larger national and international community that transcends medical practice, politics and businesses - and suggest that evaluating medical information on the web can only be done in this context.

Some studies of patient searching behaviors have indicated that patients refer to their physician for information about where to search for information on the web. [See, for example, Cotton and Gupta 12] Recognizing the potential of taking advantages of this preference for physicians as trusted sources of website recommendations, but also recognizing that physicians probably do not have time to review scales of sites, some initiatives have developed (or furthered existing) relationships with professionals. The US National Library of Medicine (NLM) has worked with professional communities to develop prescription pads for web-based information (see Fig. 1).

This project enabled NLM to inform physicians about the topics available on medlineplus. Additionally, it supports the physician and patient in post-consultation searches for health information. With this information prescription, the physician gives the patient a place to start and the term to use when searching on the web for information specific to his or her health situation-and that starting place is a government portal:

In this trial, the doctors each had their own pre-printed prescription pad. The prescription pad that we used in the first part of the pilot had room for 12 URLs. There were about 40 to choose from and they chose the ones that they saw most often in their practices. What we found is that the doctors don't want to bother with all that. They want to have their own prescription pad, they really like that. But they just want to be able to write something on it and then send people to Medlineplus. ${ }^{12}$

\footnotetext{
12 Quote taken from an interview with two employees of the US National Library of Medicine responsible for Medlineplus.gov.
} 


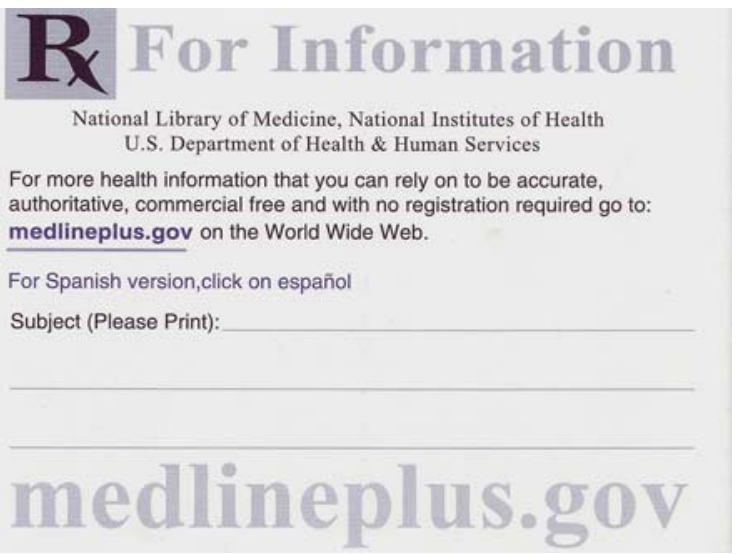

Fig. 1 Example of one version of the prescription pad that physicians can give to patients during the consultation to refer them to web-based information about a specific health topic

Finally, websites send patients back and forth between the various initiatives and tools, implicitly and explicitly endorsing one another. HON, for example, recommends that English-speaking site visitors follow a specific and narrow path to information:

To find good (English-language) healthcare information, you can bypass the all-purpose commercial search engines and go straight to healthcare portals like Health on the Net (http://www.hon.ch) or Healthfinder (http:// www.healthfinder.org/). These portals have already eliminated the irrelevant for you. A useful rule of thumb is first check out the governmental, not-forprofit and hospital Web sites, or those carrying an immediately recognizable and trusted name. ${ }^{13}$

It is interesting in this case that HON excludes more commercial search engines as a valid route to information. The message is that web tools that are general in scope, rather than specifically directed toward health information, or that are funded by commercial interests (or both) are incorrect choices because they contain too much extra "stuff" 14 and will not enable the user to find what s/he is looking for. Reliability is redefined as an issue of what is "relevant" and proper behavior involves not wasting time sifting through information and other materials that are, according to HON de facto irrelevant. Furthermore, in emphasizing that HON and the US gateway are the best types of sites, HON privileges state (implicitly working with medical) actors over other types of actors providing medical information on the web. The suggestion, then, is that engaging in good searching practices and finding/ using the "right" information means prioritizing government and medical channels.

Through these statements, the organizations affirm each other, arguing not only the importance of a joint approach to reliability, but also the importance of

\footnotetext{
13 (http://www.hon.ch/HONcode/FAQs_HONcode.html)

14 Markham [43] suggests using the term stuff to encapsulate the various things other than information that internet users can encounter when searching on the web.
} 
collaboration between different countries and regions. The risks associated with misinformation are countered with initiatives that seek to rein in information, centralizing it at certain web addresses and judging it according to politically and professionally defined criteria. One example would be the criterion for levels of readability [16] applied to sites such as Medlineplus. Another would be the use of selection criteria for information that derive from similar roots [9] or the transfer of existing publishing standards to evaluate how information is produced [1]. Website providers enable access to information that is consolidated and repackaged in a uniform format for readability and then placed on the respective site under a uniform design and structure for ease of navigation. Once again finding and using good information is made "easy" in the design of technology-specific tools.

What is interesting are the personalized messages and rhetoric of choice in which these standardized formats are embedded. Healthfinder is "your guide to reliable information," while Medlineplus provides "Trusted health information for you." Access to information gives users new choices, but these initiatives convey that responsible consumerism and reflexive use of information mean choosing narrow routes to prepackaged information. The internet offers numerous avenues to information, but "good" participation means utilizing choice to choose the routes provided by one's own government and combining these with overarching nongovernmental organizations or other non-profit organizations.

\section{Individualizing Choice Along the Way}

Both HON and the MedCIRCLE initiative have taken this one step furtheremphasizing the need to combine top-down control of information with bottom-up user choices. They have both developed special toolbars that can be downloaded and coupled on the user's internet browser (see Fig. 2 for the MedCIRCLE prototype). Such a toolbar allows the user to set his/her preferences for which components of information are most important and then gives a confidence rating for how well an individual website answers to these preferences. The toolbar gives a message that user preferences about the reliability of information are important and that users should actively set their own criteria for assessment. However, this is acceptable only once users are already searching within the confined space of preapproved sites.

The confidence rating and other information provided by the tool are only available for sites already in the HON or MedCIRCLE databases. While these types of tools suggest the importance of individual choice, they nonetheless hold individuals responsible for following the 'right' paths to information. In this sense, the discussion is not merely an issue of creating reflexive consumers, but also of judging non-reflexivity as irresponsible and deviant.

Fig. 2 Patients can download this toolbar from http://www.medcircle.org and set their own preferences for characteristics that they find important in the provision of health information 
Following the Path Back to the State

The responsibility for finding good information and avoiding the risks associated with bad information on the internet becomes collaborative and distributed. Within this context, individuals are held responsible for the choices they make, how they engage with available information and how they engage with other actors in the collaborative process. This process involves new actors, such as $\mathrm{HON}$ and MedCERTAIN/MedCIRCLE, but also longer standing actors, such as the WHO, state governments and medical associations. Reliability is created through distributing skills, information, and practices, and is intertwined with the creation of new networks that bind together the technical and social. We see this in especially in uses of internet-based technologies to further public health education.

Healthfinder, for example, sends monthly newsletters to inform its public about changes and updates to the site and about different services it provides. Each newsletter also contains a list of "health observances" for that month, each of which includes hyperlinks to special sites with more information. These observances are, where possible, coupled on the (national) holidays being celebrated in that month. For example, February is 'the month for all kinds of hearts' and the newsletter's healthy observances are all related to cardiac issues, while July's newsletter focuses on food safety tips for warm summer days and firework safety tips specifically related to the July 4th holiday. Although other months are more general, all months prescribe topics of suggested interest for the general population:

All of us, in all stages of life, can find a health observance of interest this month. April's observances range from National Donate Life Month, a request for us to consider giving another person life, to WalkAmerica, a campaign to promote the benefits of carrying babies to term, sponsored by March of Dimes, to many observances in between. ${ }^{15}$

The observances further point out special days of awareness and political activism, and also broadly publicize public health education opportunities:

The National Headache Foundation is sponsoring National Headache Awareness Week June 5-11 to recognize headache pain as a real and legitimate condition and encourage those who suffer with headaches to see a physician for proper diagnosis and treatment. This year's campaign, "Stop Migraines Before They Stop You," will feature public education activities nationwide." 16

The links that are selected for inclusion in the newsletters link largely to other parts of the Department of Health and Human Services and to other health-related government institutions (.gov domain endings), such as the National Institutes of

\footnotetext{
15 All excerpts are from 2005 newsletters. The links were omitted for ease of reading. These were: $<\mathrm{http}$ //www.organdonor.gov/donatelife.htm> and <http://www.walkamerica.org/>, for National Donate Life Month and WalkAmerica, respectively.

16 Omitted links are: <http://www.headaches.org/consumer/pressindex.html> and <http://www.headaches.org/consumer/presskit/NHAW05/FiveStrategies.pdf>
} 
Health (of which NLM is also a part) or the Centers for Disease Control and Prevention.

As these examples show, different actors have developed practices that place various elements in new and unique relationships with one another. Issues related to health become intertwined with, for example, federal holidays. The health practices of the individual are now inextricably linked with diverse forms of community participation. In this sense, health education and enrollment is no longer only or primarily about verifying online health information, but rather about diverse activities that extend beyond the online realm.

\section{Directly Linking Health Practices and Citizenship}

These initiatives are tools to help people find and/or check information and about helping lay persons become empowered, not merely through distribution of information, but also through coaching or education in how to participate more actively in the search for and use of information. Users are invited to join specific, defined communities that will, in one way or the other, protect them from misinformation and inform them about better ways to act. HON even emphasizes the strength and necessity of its partnership with lay users in able do what it sets out to do-HON cannot help lay users if the lay users do not help HON.

Additionally, there is a normative message about responsible citizenship. HON, for example, responds to individuals who follow their instructions and report (suspected) misuse of the HONcode icon by thanking them for their "sense of civic duty" and healthfinder's newsletters make the initiative much more than just a gateway, or portal, to links of organizations with information. They also serve a promotional function to keep visitors returning to the healthfinder website and getting them to link through to other government sites. Further still, they show that being an active consumer and responsible citizen involves more than merely checking the information one encounters on sites or reporting misinformation and/or misuse of seals through certain channels. The responsibility extends into all areas of daily life (from good nutrition to awareness about possible diseases) and extends beyond individuals to include not only family or friends, but also the communitybased or social responsibility that accompanies participation in educative programs, activism, or fund-raising events.

What begins as a prescription for how to search for and assess information on the web actually extends to the entire lifestyle in which these searching activities are contextualized (As Dessauer [14] notes, much of what we think of with cyberspace loses meaning and referents if it excludes the external context). Interestingly, despite the varied forms of the messages emanating from the different initiatives, each of the prescribed behaviors, such as entering the web at a location of geographical significance (within government borders), participating in a chain that actively polices adherence to an ethical code and reports misuse, or even downloading and using a browser with a special toolbar, emerges as simultaneously optional and obligatory [53]. Herein lie strains of the tensions that are suggested by both Rose and Blume and Singleton: initiatives are created and promoted under the guise of increasing choice and democratization, but the actual prescriptions that they 
carry entail more powerful suggestions about which choices (both online and off) are the "right" or "better" choices-with alternatives to those choices being (explicitly or implicitly) discouraged.

\section{Discussion}

In this paper, we discuss how political actors have enabled access to web-based information largely in terms of specific user tools; however, through these examples, we see that, as Markham [42, 43] argues, access to the internet is access not just to a tool, but to a place (emergent in for example, how the interface is designed or the level of engagement in a given activity) and a way of being (dependent on the degree to which the individual integrates the technology into his or her understanding of social construction). As providers or enablers of technology use, political actors at various levels (primarily states, but also NGOs and IGOs that provide different types of sites and tools) provide points of entry and create avenues not just to online information, but to online and offline social communities with specific rules for behaviour. This has implications for how technology is configured within the relationship between individuals and the state and other political actors. Especially important is that it highlights how the emphasis on claims of "neutrality" within the reliability debate is misplaced. Organizations such as HON or WHO, who claim their neutrality based on their international scope and/or their position outside of national governments, nonetheless carry specific normative ideas of acceptable politically or socially related user behavior. Likewise, individual state governments that claim to represent the needs of their own "general public" impose values on the information that they recommend to that public - for example, in privileging a .gov above all else, followed by a ".org" or ".edu" and reducing as much as possible endorsement of a ".com."

Existing literature arguing the need for collective solutions to reliability problems, together with the abundant presence of initiatives offering different options for interactions between lay end users and those providing assessment tools, indicate a readiness among political actors and some health professionals to engage in active teamwork with the public. There is even the possibility that this language of collaborative efforts suggests that the public is/can be seen as just another interest group balanced with physicians [30]. However, in the examples provided above, we see that partnership does not necessarily imply equal footing for each of the three types of actors. Organizations use the catch-word reliability as a rhetorical device to capture attention and enroll users-redirecting their information-seeking behaviors, but also emphasizing deeper-rooted values that situate individual health-related practices within a greater context of idealized citizenship. As such, in addition to prescriptions for use of specific tools, we find underlying prescriptions for practices that reflect good citizenship.

What, then, comprises the construction of a 'good' citizen? First and foremost a good citizen is one who is interested in a healthy lifestyle and reflects this through choosing to participate in activities such as searching for information about his/her health and the health of loved ones. Secondly, in searching for this information, the 
citizen reflects the possession of basic practical skills by choosing to align his/her practices with political actors, thereby choosing for sites that have been created or in some way reviewed by these actors. Thirdly, the citizen actively participates in the online community in which these sites are embedded. Active participation includes helping to "police" the information online by checking links and actively reporting misuse. Additionally, active participation includes extending knowledge accrued online to participate in offline community activities (activism, education, and fundraising).

This participation also forms a reciprocal relationship between the participant and the given organization-in return for making oneself available to the community, the burden to search for, find, and evaluate information is made easier. Searching can be done using tools within which information has been pre-selected and/or information can even be sent directly to the individual's personal e-mail. Both of these technical options for acquiring information also carry an implicit social promise of being taken care of-protection from misinformation or misaction due to lack of information. The readiness to participate in this partnershipthe commitment of the organization to helping protect its user community is made explicit.

Through the creation of initiatives that respond to debates about the reality of information online, organizations prescribe both online and offline behaviors, such that these are inextricably intertwined. This leads to the emergence of new collectives, counteracting the idea that internet enables people to separate activities with ease, compartmentalizing on and offline activities and leading to division. ${ }^{17}$ These collectives further counteract notions of individualization and separation from the community, as well as arguments that certain actors can be rendered irrelevant. Existing relationships become re-conceived as new alliances between medical and political actors, where internet technologies can be used to strengthen existing public education activities. Additionally, new (types of) communities emerge: families and friends or geographically concentrated communities are supplemented by communities that share aspects of visiting the same web sites and participating in the same self-policing chains-online and offline, individuals participate in communities by watching out for one another and sharing in the same activities.

Although these initiatives claim to target "all users, everywhere," they actually idealize use such that discussions about increased choice (and how this leads to patient empowerment) also carry the normative implications that "true" empowerment is only possible when the "right" choices are made. Within these discussions, individuals have the responsibility to develop skills that make them informed consumers, and the process of acquiring these skills also enables them to contribute their part to the greater civic communities in which they engage. The additional implications connoted by the terms "citizen" and "consumer" raise the question of whether these really are more suitable as replacements for the word "patient" than other suggested alternatives.

\footnotetext{
${ }_{17}$ For argumentation about how online and offline worlds are compartmentalized, see, for example, Suler [55]; for refutation of this line of argumentation, see, for example, Markham [42, 43].
} 


\section{Conclusion}

Whereas discussions of technologies and their users have largely neglected to consider the role of states (and other political actors), discussions of the relations of states and individuals have not always considered the important reciprocal effects of and on changing technologies. Discussions of skill manage to link individuals to individual technologies, but they have not successfully coupled this back on the role of states. This paper has used the discussion about the reliability of web-based information to attempt to bridge these gaps and demonstrate the integral relationship between technologies and users, states and individuals, and individuals and the development of skills. It shows that political actors, including both governmental and non-governmental organizations, make presumptions about citizen willingness to use certain technologies and, as such, utilize soft power to encourage these citizens-as-users-of-technologies to forward certain agendas.

Under the guise of democratizing ideals and suggestions of empowerment, they use policy, programs and web-based tools to encourage citizen participation. Underlying these different modes of participation, these actors are able to re-create boundaries both online and off, not only by demarcating geographical boundaries on the web, but also by supporting conventional understandings of social norms, such as the role of the medical expert as a primary leader. In so doing, they give patients the "choices" about how to behave, with strong normative undertones about rights and responsibilities associated with being informed and reflexive consumers. As others have pointed out, where medical or health-related information is discussed, an issue of power is usually at stake [37]. The power in question is generally interpreted as that of medical professionals, but this is not necessarily the only interpretation, as political actors clearly use this for their own means and ends, as well.

\section{References}

1. Adams, S. A., \& Bal R. (Accepted). Practicing reliability and the case of the iffy. Science, Technology and Human Values.

2. Adams, S. A., \& Berg, M. (2004). The nature of the net: Constructing reliability of health information on the web. IT and People, 17, 150-170.

3. Adams, S. A., \& de Bont, A. A. (2003). Notions of reliability: Considering the importance of difference in guiding patients to health care web sites. Methods of Information in Medicine, 42, 307312.

4. Adams, S. A., de Bont, A. A., \& Berg, M. (2006). Looking for answers, constructing reliability: An exploration into how Dutch patients "check" web-based health information. International Journal of Medicine Informatics, 75, 66-72.

5. Akrich, M. (1992). The de-scription of technical objects. In W. E. Bijker \& J. Law (Eds.), Shaping technology/building society (Chapter 7). Cambridge: MIT Press.

6. Anderson, J. G., Rainey, M. R., \& Eysenbach, G. (2003). The impact of cyberhealthcare on the physician-patient relationship. Journal of Medical Systems, 27, 67-84.

7. Ball, M. J., \& Lillis, J. (2001). E-health: Transforming the physician/patient relationship. International Journal of Medicine Informatics, 61, 1-10.

8. Bang, H. K. (2004). Cultural governance: Governing self-reflexive modernity. Public Administration, $82,157-190$. 
9. Baur, C., \& Deering, M. J. (2001). Commentary on the review of internet health information quality initiatives. Journal of Medical Internet Research, 3, e29. Available online: http://www.jmir.org/2001/ 4/e29/. Last Accessed: May 2002.

10. Bomba, D., \& Land, T. (2004). Constructing and validating a consumer health portal rating index. In M. Fieschi \& E. Coiera (Eds.), Proceedings of the 11th World Congress on Medical Informatics (pp. 1123-1127). 7-11 September 2004, San Francisco, CA, USA.

11. Brown, P. (2002). WHO calls for a health domain name to help consumers. British Medical Journal, $324,566$.

12. Cotton, S. R., \& Gupta, S. S. (2004). Characteristics of online and offline health information seekers and factors that discriminate between them. Social Science \& Medicine, 59, 1795-1806.

13. Doupi, P. (2005). Personalized patient education and the internet: Linking health information to the electronic patient record. The Netherlands: Erasmus University of Rotterdam, PhD Thesis.

14. Dessauer, C. (2004). New media, internet news and the news habit. In P. N. Howard \& S. Jones (Eds.), Society online. (Chapter 8, pp. 121-136.) London: Sage Publications.

15. Edgar, L., Greenberg, A., \& Remmer, J. (2002). Providing internet lessons to oncology patients and family members: A shared project. Psycho-Oncology, 11, 439-446.

16. Eng, T. R., \& Gustafson, D. H. (Eds.) (1999). Wired for health and well-being. From the science panel on interactive communication and health. Washington, DC: US Department of Health and Human Services, US Government Printing Office.

17. Eysenbach, G. (1999). Rating information on the internet can empower users to make informed decisions. British Medical Journal, 319, 385.

18. Eysenbach, G. (2000a). Consumer health informatics. British Medical Journal, 320, 1713-1716.

19. Eysenbach, G. (2000b). Towards ethical guidelines for e-health: JMIR theme issue on e-health ethics. Journal of Medical Internet Research, 2, E7. Available online: http://www.jmir.org/2000/1/e7/index.htm. Last Accessed: 20 Feb 2001.

20. Eysenbach, G. (2002). Infodemiology: The epidemiology of (mis)information. The American Journal of Medicine, 113, 763-765.

21. Eysenbach, G., \& Kohler, C. (2002). Database of adverse events related to the internet has been set up. British Medical Journal, 324, 238.

22. Ferguson, T. (2002). From patients to end users. British Medical Journal, 324(7337), 555-556.

23. Fogg, B. J., Soohoo, C., Danielsen, D., Marable, L., Stanford, J., \& Tauber, E. R. (2002). How do people evaluate a web site's credibility? Results from a Large Study. Report from the Stanford University Persuasive Technology Lab, Consumer Web Watch, and Sliced Bread Design, October.

24. Fox, N. J., Ward, K. J., \& O'Rourke, A. J. (2005). The 'expert patient': Empowerment or medical dominance? The case of weight loss, pharmaceutical drugs and the internet. Social Science and Medicine, 30, 1299-1309.

25. Gustafson, D. H., \& Wyatt, J. C. (2004). Evaluation of ehealth systems and services. British Medical Journal, 328, 1150.

26. Halavais, A. (2000). National borders on the world wide web. New Media and Society, 2(1), 7-28.

27. Hardey, M. (1999). Doctor in the house: The internet as a source of lay health knowledge and the challenge to expertise. Sociology of Health and Illness, 21, 820-835.

28. Hardey, M. (2001). E-health: The internet and the transformation of patients into consumers and producers of health knowledge. Information, Communication and Society, 4, 388-405.

29. Hargittai, E. (2004). The changing online landscape: From free-for-all to commerical gatekeeping. In P. Day \& D. Schuler (Eds.), Community practice in the network society: Local actions global interaction (pp. 66-76). New York: Routledge.

30. Harrison, S., \& Mort, M. (1998). Which champions, which people? Public and user involvement in health care as a technology of legitimation. Social Policy and Administration, 32, 60-70.

31. Henwood, F., Wyatt, S., Hart, A., \& Smith, J. (2002). Turned on or turned off? Accessing health information on the internet. Scandinavian Journal for Information Systems, 14, 79-90.

32. Henwood, F., Wyatt, S., Hart, A., \& Smith, J. (2003). Ignorance is bliss sometimes: Constraints on the emergence of the "informed patient" in the changing landscapes of health information. Sociology of Health and Illness, 25, 589-607.

33. Jadad, A. R. (1999). Promoting partnerships: Challenges for the internet age. British Medical Journal, 319, 761-764.

34. Kiley, R. (2000). Quackery on the web. He@lth information on the internet, June 9-10. 
35. Kiley, R. (2002). Some evidence exists that the internet does harm health. Editorial letter. British Medical Journal, 324, 238.

36. Kivits, J. (2002). Health information on the internet: An investigation of the methodological dilemmas and opportunities offered by e-mail interviewing. Paper presented at the International Conference of the Association of Internet Researchers, IR 3.0: Net/Work/Theory, October, 2002. Maastricht, The Netherlands.

37. Kivits, J. (2004). Researching the 'informed patient': The case of online health information seekers. Information, Communication and Society, 7, 510-530.

38. Klecun-Debrowska, E., \& Cornford, T. (2000). Telehealth acquires meanings: Information and communication technologies within health policy. Information Systems Journal, 10, 41-63.

39. Latour, B. (1987). Science in action. Cambridge, Massachusetts: Harvard University Press.

40. Latour, B. (1991). Technology is society made durable. In J. Law (Ed.), A sociology of monsters: Essays on power, technology and domination (pp. 103-131). New York: Routledge.

41. Lupton, D. (1997). Consumerism, reflexivity and the medical encounter. Social Science \& Medicine, 45, 373-381.

42. Markham, A. N. (2002). The internet as research context. In C. Seale, J. Gubrium, G. Gobo \& D. Silverman (Eds.), (2003), Qualitative research practice. London: Sage. Also available online: http:// faculty.uvi.edu/users/amarkha/. Last Accessed: 14 August 2005.

43. Markham, A. N. (2003). Metaphors reflecting and shaping the reality of the internet: Tool, place, way of being. Available online: http://faculty.uvi.edu/users/amarkha/. Last Accessed: 14 August 2005.

44. Miller, T. E., \& Reents, S. (1998). The health care industry in transition: The online mandate to change. Report from Cyber Dialogue Incorporated.

45. Nater, T., \& Boyer, C. (2000). Letter to the editor: Debate about evaluation and monitoring of sites carrying the HONlogo. Includes a reply from the editor. Journal of Medical Internet Research, 2, e13. Available online: http://www.jmir.org/2000/2/e13/index.htm Last Accessed: 5 February 2002.

46. Oudshoorn, N., \& Pinch, T. (Eds.) (2003). How users matter. Cambridge, Massachusetts: The MIT Press.

47. Oudshoorn, N., Rommes, E., \& Stienstra, M. (2004). Configuring the user as everybody:gender and design cultures in information and communication technologies. Science Technology Human Values, 29, 30-63.

48. Peterson, G., Aslani P., \& Williams K. A. (2003). How do consumers search for and appraise information on medicines on the internet? A qualitative study using focus groups. Journal of Medical Internet Research, 5, e33 Available online: http://www.jmir.org/2003/4/e33/ Last Accessed: 2 January 2005.

49. Pitts, V. (2004). Illness and internet empowerment: Writing and reading breast cancer in cyberspace. Health, 8, 33-59.

50. Rigby, M., Forsstrom, J., Roberts, R., \& Wyatt, J. (2001). Verifying quality and safety in health informatics services. British Medical Journal, 323, 552-556.

51. Risk, A. (2002). Commentary: On the way to quality. British Medical Journal, 324, 601-602.

52. Rose, D., \& Blume, S. (2003). Citizens as users of technology: An exploratory study of vaccines and vaccination. In N. Oudshoorn \& T. Pinch (Eds.), How users matter (Chapter 5, pp. 103-131). Cambridge, Massachusetts: The MIT Press.

53. Singleton, V. (2005). The promise of public health: Vulnerable policy and lazy citizens. Society and Space, 23, 771-786.

54. Stanford, J., Tauber, E. R., Fogg, B. J., \& Marable, L. (2002). Experts versus online consumers: A comparative credibility study of health and finance websites. Report from sliced bread design, the Stanford Persuasive Technology Lab and Consumer Web Watch. October.

55. Suler, J. (2000). Bringing online and offline living together: The integration principle. Version 1.0, posted in January. Available online: http://www.rider.edu/users/suler/psycyber/integrate.html. Last Accessed: 10 November 2001.

56. Winner, L. (1980). Do artifacts have politics? Daedelus, 109, 121-136.

57. World Health Organization. (2005). Websites providing information on vaccine safety recognized for complying with good information practices. Press Release. Available online: http://www.who.int/ mediacentre/news/notes/2005/np09/en/index.html. Last Accessed 16 August 2005.

58. Woolgar, S. (1991). Configuring the user: The case of usability trials. In J. Law (Ed.), A sociology of monsters: Essays on power, technology and domination (Chapter 3, pp. 57-99). London: Routledge. 